\title{
Perforation of the right ventricle and cardiac tamponade caused by a venous catheter
}

\author{
Alfonso IgLESIAS \\ M.D. \\ JUAN J. RUFILANCHAS \\ M.D.
}

José M. MAROŇAS

M.D.

DiEgo Figuera

M.D., F.A.C.S.

\begin{abstract}
Depto Cirurgia Cardiovascular, Clinica Puerta de Hierro, Autonomous University of Madrid, Madrid, Spain
\end{abstract}

\begin{abstract}
Summary
A case is reported in which a venous catheter perforated the right ventricle and caused cardiac tamponade. Methods recommended to avoid such complications include limiting the length of the radio-opaque catheter, and modifications to the catheter tip.
\end{abstract}

\section{Introduction}

Although the insertion of a central venous catheter for such purposes as central venous pressure monitoring, fluid administration, cardiac catheterization, and the implantation of intravenous pacemakers is a widely established procedure, its use is not exempt from complications.

The case of a fatal complication of central venous catheterization is now reported.

\section{Case report}

A 54-year-old white woman with mitral stenosis, was admitted for open mitral commissurotomy. A semi-rigid catheter was inserted through the right brachial vein until the tip was estimated to lie in the superior vena cava. Patency of the catheter lumen was maintained with a slow drip of isotonic glucose. After $4 \mathrm{hr}$, symptoms consistent with low cardiac output syndrome supervened. Chest X-ray was similar to previous films but the catheter tip was situated in the right ventricle; the catheter was therefore pulled out $10 \mathrm{~cm}$. Electrocardiogram showed atrial fibrillation. Central venous pressure was $7 \mathrm{mmHg}$. Arterial blood gases showed mild hypoxaemia. The patient was treated with digitalis and diuretics. As the response was poor, isoprenaline was added and this was followed by haemodynamic improvement. Six hours later the patient complained of chest pain and suddenly developed severe hypotension, mental confusion, bradycardia of 35 beats/ min followed by cardiac arrest. No response to

Correspondence: Dr A. Iglesias, Depto Cirurgia Cardiovascular, Clinica Puerta de Hierro, San Martín de Porres, 4, Madrid 35, Spain. standard resuscitation procedures was obtained, and a left thoracotomy was performed. The pericardial sac was found to be distended and filled with $850 \mathrm{ml}$ of freshly coagulated blood which was removed. The heart was in ventricular fibrillation and responded satisfactorily to electrical defibrillation. The patient, however, remained comatose and hypotensive and died $8 \mathrm{hr}$ later. At post-mortem, a perforation was observed in the right ventricle anterior wall which was attributed to the catheter. No signs of recent myocardial infarction were observed.

\section{Discussion}

Cardiac tamponade is one of the possible complications of central venous catheterization, and demands an urgent decompression by pericardiocentesis. In spite of this knowledge, of the twenty cases found in the literature (Brandt et al., 1970; Brown and Kent, 1956; Greenhall, Blewitt and McMahon, 1975; Henzel and DeWeese, 1971; Homesely and Zelenik, 1971; Johnson, 1966) and including this one, eighteen died. The clinical evolution was similar in all: a development of a rapidly progressive low cardiac output syndrome within a few hours or days after insertion of the catheter. Radiological studies are usually of little value although they may be diagnostic in some cases (Homesley and Zetenik, 1971). Cardiac tamponade should be suspected in any patient with an indwelling central venous catheter who abruptly develops a low cardiac output syndrome.

The use of radio-opaque catheters of a length unlikely to reach to below the level of the pericardial sac, the radiological demonstration of location in the superior vena cava, the omission of bevelled edges at the catheter tip, the avoidance of movement of the body and catheter tip (Brandt et al., 1970), the fixation of the catheter at its insertion site in order to reduce catheter movement, are measures that should decrease the risk of perforating the heart in patients such as the one described. 


\section{References}

Brandt, R.I., Foley, W.J., Fink, G.H. \& Regan, W.J. (1970) Mechanism of perforation of the heart with production of hydropericardium by a venous catheter and its prevention. American Journal of Surgery, 119, 311.

Brown, C.A. \& Kent, A. (1956) Perforation of right ventricle by polyethylene catheter. Southern Medical Journal, 49, 466.

Greenhall, M.J., Blewitt, R.W. \& McMahon, M.J. (1975) Cardiac tamponade and central venous catheter. British Medical Journal, 2, 595.
Henzel, J.H. \& DeWeese, M.J. (1971) Morbid and mortal complications associated with prolonged central venous cannulation. Awareness, recognition and prevention. American Journal of Surgery, 121, 600.

Homesley, H.D. \& ZeleniK, J.S. (1971) Hazards of central venous pressure monitoring: pericardial tamponade, American Journal of Obstetrics and Gynecology, 109, 1216.

Johnson, C.E. (1966) Perforation of right atrium by a polyethylene catheter. Journal of the American Medical Association, 195, 176.

\section{Pneumothorax and hydrothorax after subclavian vein cannulation}

\author{
STEPHEN HolT \\ M.B., M.R.C.P.
}

\author{
ElizABeth Myerscough \\ M.B., Ch.B.
}

Sefton General Hospital, Liverpool L15 2HE

\begin{abstract}
Summary
A patient is described who developed a right pneumothorax and a left hydrothorax following percutaneous subclavian vein cannulation. The prevention, diagnosis and treatment of this complication are discussed.

\section{Introduction}

Intravenous nutrition through an indwelling venous catheter is an accepted procedure. Large vein catheters provide a stable route of administration for prolonged parenteral therapy. Several approaches for central venous cannulation have been used including the antecubital, internal and external jugular, femoral and subclavian veins, but no method is free of complication (Thomas, Carter and Lowder, 1969). The subclavian route has gained popularity because of easy access, a large venous flow and a reliable patency. Catheter stability and tolerance is good and infection is not generally a problem. Pneumothorax is a well documented complication of subclavian vein cannulation (Walker and Sanders, 1969). Other infrequent hazards include hydrothorax, haemothorax, massive subcutaneous emphysema, arteriovenous fistula, brachial plexus injury and air embolism (Latimer, 1971). The occurrence of two of these complications in one patient has not been previously reported.
\end{abstract}

Correspondence: Dr S. Holt, Liverpool Regional Cardiac Centre, Sefton General Hospital, Smithdown Road, Liverpool L15 $2 \mathrm{HE}$.

\section{Case report}

A 64-year-old female with severe endogenous depression had become dehydrated after a prolonged period of self-starvation and refusal to drink. The subclavian vein was cannulated using a percutaneous supraclavicular approach for the administration of hyperosmolar parenteral alimentation.

\section{Technique}

A no. 19 Seldinger needle $7.7 \mathrm{~cm}$ long, which is made up of an external cannula and an internal section containing a stylet with a bevelled point, was used. The needle was introduced into the right supraclavicular fossa at the clavisternomastoid angle but penetration of the right subclavian vein was not achieved. The procedure was repeated on the left side and the left subclavian vein was entered with ease. After removal of the central needle and stylet, blood was aspirated freely into a syringe. A spring guide wire, $80 \mathrm{~cm}$ long, with an external diameter of $0.889 \mathrm{~mm}$, was passed through into the vein under $\mathrm{X}$-ray control. A compound percutaneous catheter introducer, with an 8.5 FG (French gauge) outer sheath fitting over a 6-FG catheter, was inserted over the guide wire after the removal of the Seldinger cannula. The wire and inner catheter were then removed and a non-radiopaque catheter ( 5 FG) was introduced into the vein and its position checked by X-ray screening after injection of sodium diatrizoate. The catheter introducer was withdrawn from 